\title{
The coming of age of the mitochondria-ER contact: a matter of thickness
}

\author{
M Giacomello, ${ }^{* 1,2}$ and L Pellegriniं ${ }^{*, 3,4}$
}

The sites of near-contact between the mitochondrion and the endoplasmic reticulum (ER) have earned a lot of attention due to their key role in the maintenance of lipid and calcium $\left(\mathrm{Ca}^{2+}\right)$ homeostasis, in the initiation of autophagy and mitochondrial division, and in sensing metabolic shifts. At these sites, typically called MAMs (mitochondria-associated ER membranes) or MERCs (mitochondria-ER contacts), the organelles juxtapose at a distance that can range from $\sim 10$ to $\sim 50 \mathrm{~nm}$. The multifunctional role of this subcellular compartment is puzzling; further, recent studies have shown that mitochondria-ER contacts are highly plastic structures that remodel upon metabolic transitions and that their activity in controlling lipid homeostasis could be involved in Alzheimer's disease pathogenesis. This review aims at integrating the functions of this subcellular compartment to its most characterizing and unexplored structural parameter, their 'thickness': that is, the width of the cleft that separates the cytosolic face of the outer mitochondrial membrane from that of the ER. We describe and discuss the reasons why the thickness of a MERC should be considered a regulated structural parameter of the cell that defines and controls its function. Further, we propose a MERC classification that will help organize the expanding field of MERCs biology and of their role in cell physiology and human disease.

Cell Death and Differentiation (2016) 23, 1417-1427; doi:10.1038/cdd.2016.52; published online 24 June 2016

Facts

- Mitochondria form contacts with the smooth endoplasmic reticulum (ER; mitochondria-ER contacts, MERCs) as well with the ribosome-containing rough ER (ribo-MERCs).

- MERCs are dynamic structures that respond to the metabolic state of the cell.

- The key structural elements of a MERC are the size of its area and the width of the gap that separates the cytosolic face of the mitochondrion and of the ER (MERC thickness).

- MERCs size and thickness are regulated parameters of the cell.

- The thickness of a MERC likely determines its cellular function.

- The thickness of a MERC ranges from $\approx 10$ to $\approx 50 \mathrm{~nm}$; the thickness of a ribo-MERC ranges from $\approx 50$ to $\approx 80 \mathrm{~nm}$.

- We have proposed a 'MERC nomenclature' that is based on merging the thickness of this structure to the diverse array of cellular processes that it can regulate.

- The isolation of the MERCs that is obtainable through biophysical protocols yields the mitochondria-associated ER membranes (MAMs).

\section{Open Questions}

- What are the molecular mechanisms governing the structural plasticity of the MERCs? Are they linked to human diseases?

- How do metabolic changes instruct the MERCs to change size and thickness?

- What determines the function of a MERC? Can one type of MERC have more than one function?

- What are the proteins that bridge the gap between the mitochondria and the ER at the MERCs? Do different types of MERC have different proteomes?

- What is the function of the ribo-MERCs? Are they also a dynamic and regulated parameter of the cell?

\section{Introduction: of MERCs and MAMs}

The execution of several biological processes, like phospholipid biosynthesis and $\mathrm{Ca}^{2+}$ signaling, require two different organelles to be in close proximity. At these sites of 'contact' the organelles are never really touching each other, but the

\footnotetext{
${ }^{1}$ Department of Biology, Università di Padova, Padua, Italy; ${ }^{2}$ Venetian Institute of Molecular Medicine, Padua, Italy; ${ }^{3}$ Department of Molecular Biology, Medical Biochemistry and Pathology, Faculty of Medicine, Universitè Laval, Quebec, Québec, Canada and ${ }^{4}$ Mitochondria Biology Laboratory, CRIUSMQ, Quebec, Québec, Canada *Corresponding author: M Giacomello or L Pellegrini, Department of Molecular Biology, Medical Biochemistry and Pathology, Universitè Laval, CRIUSMQ, Room F-6500, 2601 Ch. de la Canardiere, Quebec G1J 2G3, Québec, Canada. Tel/Fax: +1 14186635000 ext. 6879; E-mail: marta.giacomello@ bio.unipd.it or luca.pellegrini@ fmed.ulaval.ca Abbreviations: $\mathrm{AD}$, Alzheimer's disease; $\mathrm{Ca}^{2+}$, calcium; ER, endoplasmic reticulum; IMM, inner mitochondrial membrane; IP3R, inositol 3-phosphate receptor; LR, lipid raft; MAMs, mitochondria-associated ER membranes; MCU, mitochondrial calcium uniporter; MERCs, mitochondria-ER contacts; MEFs, mouse embryonic fibroblasts; Mfn2, Mitofusin-2; MiD49/51, mitochondrial dynamics proteins of 49 and $51 \mathrm{kDa}$; mTORC, mammalian target of rapamycin complex; PERK, protein kinase RNAlike endoplasmic reticulum kinase; OMM, outer mitochondrial membrane; RER, rough endoplasmic reticulum; SCO1/2, synthesis of cytochrome coxidase, factors 1 and 2; ULK, UNC51-like kinase; VDAC, voltage-dependent anion channel

Received 27.1.16; revised 02.5.16; accepted 05.5.16; Edited by N Chandel; published online 24.6.16
} 
a

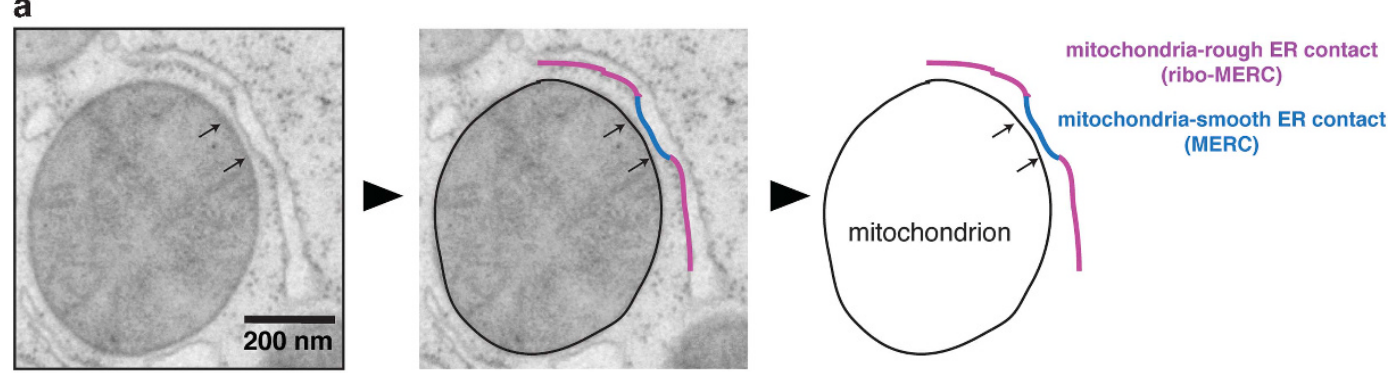

b

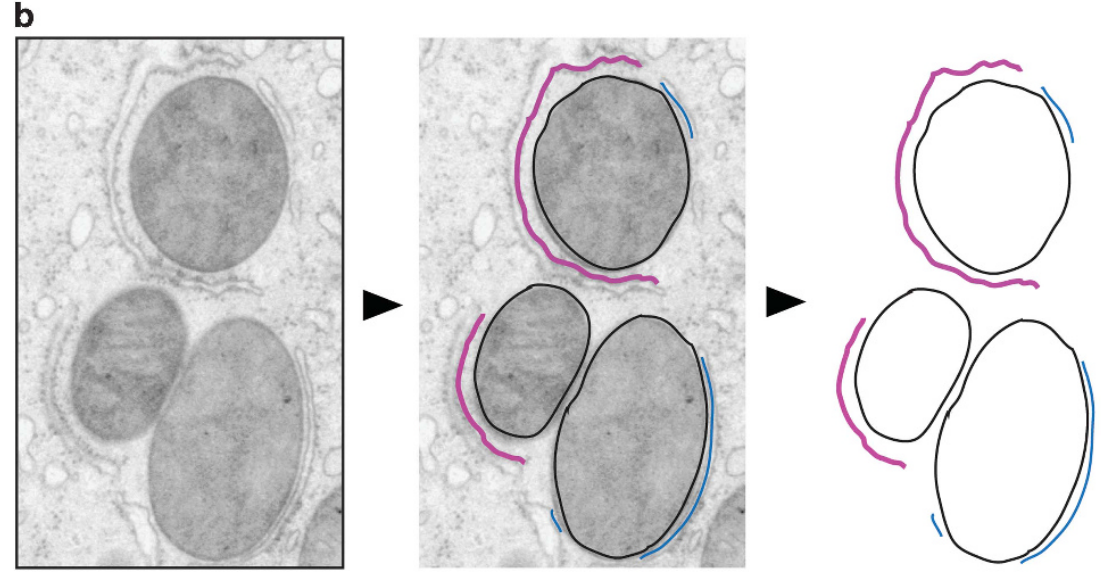

Figure 1 Mitochondria form sites of contact with the smooth ER (MERCs) and with the ribosome-containing rough ER (ribo-MERCs). These two types of structures can exist as part of a single unit (a) or as separate entities (b). MERCs are the most-studied ones because they are responsible for ions and lipid transfer between the two organelles; ribo-MERCs, instead, have been so far poorly studied and their function is still unknown. Both types of mitochondria-ER contacts typically extend over several hundreds nanometer in length. In mouse liver hepatocytes (shown here), the vast majority of the MERCs are characterized by having the two organelles juxtaposed at a constant distance that varies between $\sim 10$ and $\sim 25 \mathrm{~nm}$ for the MERCs, and $\sim 50$ to $80 \mathrm{~nm}$ for the ribo-MERCs. The length and the thickness of the MERC change during hepatic metabolic shifts, ${ }^{4}$ indicating that they are regulated structural parameters of the cell. The reason behind the structural plasticity of the MERCs remains unknown, but it could be a key part of the mitochondrial adaptive response that contributes to build the metabolic flexibility of the cell|1

perpendicular distance that separates them is narrow, typically from 10 to $50 \mathrm{~nm}$. The most-studied interorganellar contact is the one occurring between the mitochondrion and the ER: the MERC.

In electron microscopy (EM) images, a MERC appears as the juxtaposition of the cytosolic face of the outer mitochondrial membrane (OMM) to that of the smooth $\mathrm{ER}^{1-3}$ (Figure 1); however, since the ribosome-containing rough ER also forms contacts with mitochondria (Figure 1), we call this type of interorganellar association as ribo-MERC. In either case, the two membranes run parallel to each other for several hundreds nanometers of length, ${ }^{4}$ separated by a cleft whose width ranges from $\approx 10$ to $\approx 80 \mathrm{~nm}$ (Figure 1 ).

The number, length, and 'thickness' of the MERC are regulated parameters of the cell; they contribute to define its biological function and provide the elements on which the cell can regulate the activity of this subcellular compartment. Few papers have provided experimental proof of MERCs dynamism. Bravo et al. ${ }^{5}$ showed that, in HeLa cells, early phases of ER stress are accompanied by a 2.5 -fold increase in the number of close ER-mitochondria contacts. Csordas et al. ${ }^{6}$ showed by EM that exposure of RBL-2H3 cells to apoptotic stimuli decreased the average distance/thickness between mitochondria and ER from $28.2 \mathrm{~nm}$ to $\cong 20 \mathrm{~nm}$. Our cryo-EM imaging and in vivo postprandial studies show that in the mouse liver the thickness and the length of the MERCs depends on the metabolic state of the hepatocyte; ${ }^{4}$ more specifically, when the mTORC1 nutrient-sensing pathway disengages the average MERCs thickness increases from 14 to $20 \mathrm{~nm}$, and the average length expands from 145 to $270 \mathrm{~nm}$. Under these metabolic states the number of MERCs does not change, indicating that the execution of the underlying physiological programs does not depend on the density of the MERCs but, rather, by the proportion of mitochondrial surface that is 'enveloped' by the smooth ER, which increases from 4 to $11 \%$ when nutrients drop. ${ }^{4}$ Thus, MERCs structure adapts to metabolic transitions, suggesting that MERC activity and dynamics are interdependent.

Whether different cell types are characterized by distinct structural signatures of their MERCs (number, length, and thickness) remains unknown, but this might be the case. In mouse hepatocytes at least one mitochondrion in four has a MERC; ${ }^{4}$ however, in mitochondria sitting at the synapses of neurons of the dentate gyrus of the mouse brain MERCs are typically absent (our unpublished observations). In HeLa cells, the surface of the mitochondrial network in apposition to the ER ranges from 5 to $20 \%$ of the total; ${ }^{7}$ however, in mouse liver cells MERCs cover 4 to $11 \%$ of the mitochondrial surface, depending on the metabolic state of the cell. ${ }^{4}$ These findings support a model where the MERCs are a dynamic 
a

average MERC width

approx. $22 \mathrm{~nm}$
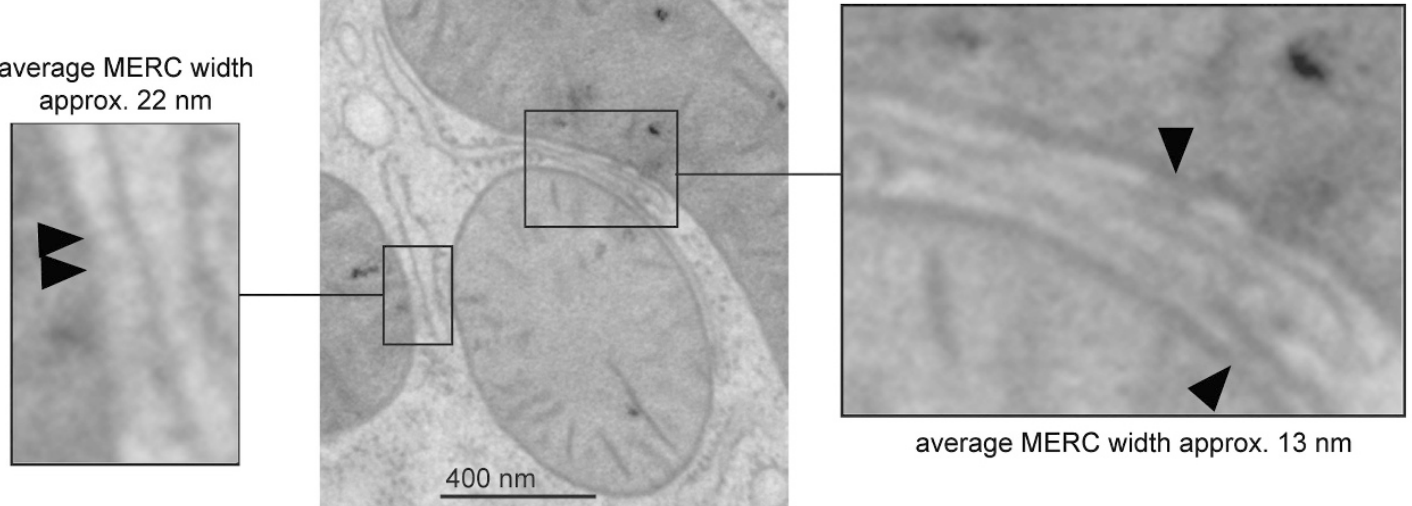

average MERC width approx. $13 \mathrm{~nm}$

b

average MERC width approx. $15 \mathrm{~nm}$

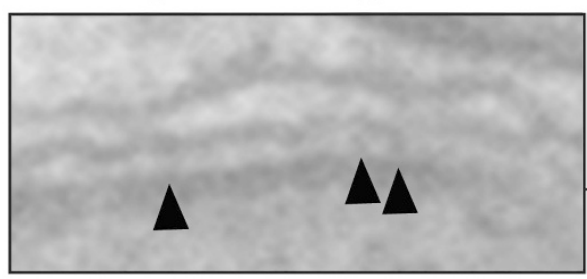

c

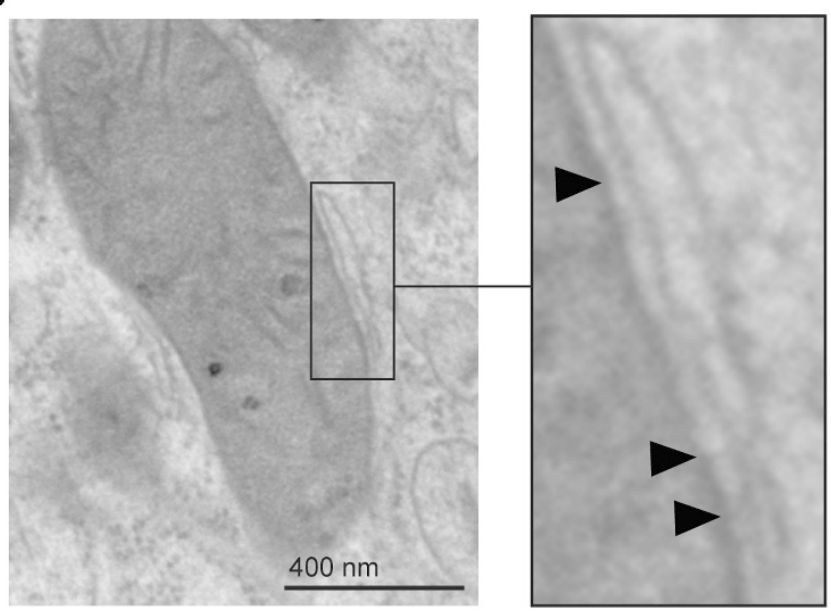

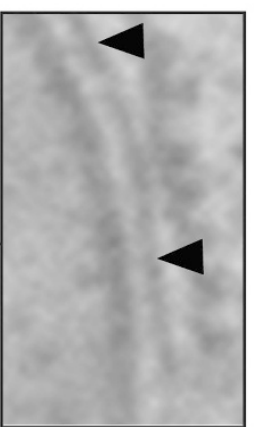

average MERC width approx. $10 \mathrm{~nm}$ average MERC width

approx. $15 \mathrm{~nm}$

Figure 2 MERCs of various thicknesses are filled by electron-dense structures. Cryo-EM images from mouse hepatocytes ${ }^{4}$ showing MERC clefts of different average width decorated by electron-dense strcutures (a-c; arrows); these structures are likely formed by proteins that tether the two membranes together and that form the complexes that drive the function of the MERC

compartment whose ultrastructural organization is integrated in the regulation of key fundamental processes of cell biology and metabolism.

High-magnification EM imaging of the MERC cleft shows the presence of electron-dense areas (Figure 2); these structures are widely accepted to be protein complexes that tether together the two organelles, ${ }^{6,8}$ a possibility that has its raison d'etre in the fact that their membranes run parallel to each other for hundreds of nanometers, ${ }^{4}$ covering several $\mu \mathrm{m}^{2}$ of ER and mitochondrial surface: such a highly organized 
structure can only be achieved through specialized protein complexes that keep the membranes tethered together, thereby allowing at a well-defined distance. The membranes that form the MERCs can be purified using subcellular fractionation techniques and density gradients of Percoll or Optiprep; ${ }^{9,10}$ at which point they are called MAMs. ${ }^{10-15}$ MERCs and MAMs are sometime used as synonyms, but they do not mean the same thing. The term MERC describes the architecture and ultrastructural organization of the site of contact between the two organelles, which can be visualized by EM and that provide the physical platform for the execution of specific cellular functions. The term MAM, instead, being the product of the biophysical enrichment of mitochondria and ER membranes tethered together, describes the repertoire of proteins and lipids that form the MERCs. The MAMs, therefore, embody the biochemical essence of the MERCs. We propose to use the term MAMs when describing the results of experiments deriving from the biophysical purification, and subsequent biochemical/ functional characterization, of mitochondria-ER contacts; and the term MERC when describing the structure and function of this compartment, or when providing imaging data that describe it. We also propose to use the term 'lipid-MERC' when referring to a MERC involved in lipid transfer/biosynthesis; ' $\mathrm{Ca}^{2+}-\mathrm{MERC}$ ' to a MERC implicated in $\mathrm{Ca}^{2+}$ transfer; 'fission-MERC' and 'phago-MERC' to a MERC engaged in mitochondrial division and autophagosome formation, respectively.

MERCs and MAMs are at the center of intense investigations for their role in lipid and $\mathrm{Ca}^{2+}$ homeostasis and for their implication in the etiology of metabolic and degenerative disorders. ${ }^{15-18}$ Although many papers have explored their function, only few have analyzed in details their structure, number and length. However, importantly, little attention has been given to the thickness of the MERC; that is, the width of the cleft separating the ER from the OMM. However, to date little attention has been given to the thickness of the MERC; arguably the only structural parameter that regulates the function of the $M E R C$, which ultimately is that of regulating the transfer of ions and molecules between different organelles. Whether the MERCs thickness is a fixed or dynamic parameter also remains poorly explored, although multiple evidence suggest that cells use the structural plasticity of the MERCs to regulate their activity, a possibility supported by the notion that ER stress doubles the number of tight MERCs ${ }^{6}$ and increases ER-mitochondria $\mathrm{Ca}^{2+}$ flux, leading to higher oxygen consumption within mitochondria. ${ }^{5}$

\section{Of MERCs Thickness and The Diffusion Laws of Einstein and Fick}

The passage of an ion or of a molecule through a lipid bilayer occurs first through specialized channels or transporters; then, the movement of the ion/molecule proceeds either by active transport (e.g., microtubule-mediated transport), or by diffusion. Both types of movements have limits. Active transport is an energetically expensive process that, however, can ensure a directionally controlled movement through long distances; instead, diffusion is a zero-energy process that allows the stochastic movement of ions/molecules through short distances. Although active transport at the MERCs has not yet been reported, diffusion is undoubtedly involved in $\mathrm{Ca}^{2+}$ transfer from the $\mathrm{Ca}^{2+}$-releasing unit on the $\mathrm{ER}$ membrane to the low-affinity mitochondrial $\mathrm{Ca}^{2+}$ Uniporter (MCU). ${ }^{19,20}$ Therefore, the $\mathrm{Ca}^{2+}$-exchange function of the MERCs is subjected to the laws of physics, ${ }^{21}$ which are described in Fick's and Einstein's diffusion theories. According to Fick's laws, $\mathrm{Ca}^{2+}$ will move from regions of high concentration on the ER membrane to regions of low concentration on the mitochondrial surface, forming a concentration gradient that changes with time. Einstein's diffusion equation ${ }^{22}$ predicts that doubling the typical MERCs cleft would slow down the $\mathrm{Ca}^{2+}$ diffusion time about four folds; therefore, the MERCs thickness dictates the existence, the extent and the frequency of $\mathrm{Ca}^{2+}$ transfer between these organelles. The average width of a MERC that coordinates $\mathrm{Ca}^{2+}$-transfer (herein denoted as $\mathrm{Ca}^{2+}-\mathrm{MERC}$ ) is $\cong 15 \mathrm{~nm}$. ${ }^{6,23}$ To date, it is not known how a wider distance between the ER and the OMM would impact on $\mathrm{Ca}^{2+}$ transfer. However, the $\mathrm{Ca}^{2+}$-transfer machinery is formed by ER- and OMM-resident proteins that, together, form a complex (inositol 3-phosphate receptor (IP3R)-grp75-VDAC) that spans the two membranes; ${ }^{24}$ therefore, it is likely that a MERC cleft wider than $25 \mathrm{~nm}$ would not consent the assembly of the IP3R-grp75-VDAC complex, thereby compromising the mitochondria-ER $\mathrm{Ca}^{2+}$ transfer. ${ }^{21}$ Doubling the cleft from 15 to $30 \mathrm{~nm}$ would theoretically bring $\left[\mathrm{Ca}^{2+}\right]$ on the OMM surface from $\cong 15 \mu \mathrm{M}$, which is the value of $\left[\mathrm{Ca}^{2+}\right]$ microdomains measured in cell-based assays, ${ }^{23,25}$ to $\cong 3 \mu \mathrm{M} ;{ }^{26}$ the latter value is well below the $K_{\mathrm{m}}$ of MCU $(20-30 \mu \mathrm{M})$, and would hamper $\mathrm{Ca}^{2+}$ uptake. A wider cleft would also increase the time required for $\mathrm{Ca}^{2+}$ ions to diffuse from the mouth of the IP3R to the mitochondrion and, by implication, the time required to build $\mathrm{MCU}$-responsive $\left[\mathrm{Ca}^{2+}\right]$. Thus, changes in the width of a $\mathrm{Ca}^{2+}-\mathrm{MERC}$ might regulate $\mathrm{Ca}^{2+}$ signaling activity, supporting a model where changes in the MERCs width accompany physiological or metabolic transitions. ${ }^{27,28}$ Consistent with this possibility, Csordas et al. showed that RBL-2H3 cells subjected to proapoptotic stimuli respond by narrowing the MERCs cleft from $28 \pm 2$ to $19 \pm 2 \mathrm{~nm} ;{ }^{6}$ however, whether this plasticity also occurs in vivo and during physiological responses remains unknown. To gain insights on MERCs dynamics, we returned to the cryo-EM images acquired for our recent study, where we reported that MERCs double in length during fasting. ${ }^{4}$ Under these conditions, the MERC cleft widens $\cong 45 \%$, 'opening' from $14.2 \pm 0.5$ to $20.8 \pm 1.2 \mathrm{~nm}$ ( 2 and $5 \mathrm{~h}$ postprandial, respectively; $n=50$; $\left.{ }^{* * *} P<0.001\right)$. These data indicate that the structural plasticity of the MERC cleft accompanies changes in cell metabolism, possibly as part of an adaptive process, consistent with the notion that mitochondrial ultrastructure and bioenergetics are tightly integrated to cell physiology. ${ }^{27-29}$ Impairing the remodeling of the MERC thickness might, therefore, underlie the development of those pathologies that have been linked to altered MERCs activity, such as Alzheimer's disease (AD), ${ }^{30}$ Parkinson's disease ${ }^{31}$ and cancer. ${ }^{32}$

\section{The Ion-MERC: An Ion Exchanger Platform}

It has been long known that mitochondria can uptake $\mathrm{Ca}^{2+}$ and accumulate it to regulate enzymes that are central to the bioenergetics and biosynthetic output of the organelle 
(e.g., pyruvate, alpha-ketoglutarate and isocitrate dehydrogenase). ${ }^{33-35}$ However, the long-standing puzzle of how mitochondria pick up $\mathrm{Ca}^{2+}$ using the low-affinity $\mathrm{MCU}$ has been solved only recently. Pioneering studies proposed a model where microdomains of high $\left[\mathrm{Ca}^{2+}\right]$ are formed by the release of the ion from the lumen of the ER directly on the mitochondrial surface at sites of close proximity between these organelles. ${ }^{7,25,36} \mathrm{Ca}^{2+}$ uptake by $\mathrm{MCU},{ }^{19,20}$ although possible without physical coupling of the ER to the mitochondrion, is favored when the ER membrane is facing the OMM at a narrow distance of $\approx 15 \mathrm{~nm} ;{ }^{6,23}$ artificially reducing the width of the cleft between the two organelles (below $7 \mathrm{~nm}$ ) abated by $80 \%$ mitochondria $\mathrm{Ca}^{2+}$ uptake, ${ }^{23}$ possibly due to steric hindrance: the IP3R, which releases $\mathrm{Ca}^{2+}$, is estimated to protrude $10 \mathrm{~nm}$ from the ER membrane; ${ }^{37}$ a juxtaposition $<7 \mathrm{~nm}$ wide would not be sufficient to host the ER-OMM Ca ${ }^{2+}$ transfer machinery, which is composed by the IP3R in complex with grp75 and voltage-dependent anion channel (VDAC). ${ }^{21,23,24}$ As explained above, a wider cleft of $30 \mathrm{~nm}$ would also hamper $\mathrm{Ca}^{2+}$ uptake. It appears, therefore, that efficient $\mathrm{Ca}^{2+}$ transfer at the $\mathrm{Ca}^{2+}-\mathrm{MERC}$ can occur when the membranes of the organelles are properly spaced apart, possibly at a distance of $12-24 \mathrm{~nm}$ : a shorter or a wider distance between the organelles would impair $\mathrm{Ca}^{2+}$ transfer for different reasons. On the basis of Fick and Einstein's laws, any change in the thickness of the $\mathrm{Ca}^{2+}-\mathrm{MERC}$ within the range of $12-24 \mathrm{~nm}$ is also poised to have an effect in the rate of $\mathrm{Ca}^{2+}$ uptake. Therefore, changing the thickness of the $\mathrm{Ca}^{2+}-\mathrm{MERC}$ would impact on the activity of several enzymes of the Krebs cycle and on the strength of the IP3R $\mathrm{Ca}^{2+}$ signaling pathway, which are critical in controlling cell bioenergetics. ${ }^{28}$ It is wellestablished that $\mathrm{Ca}^{2+}$ transfer and signaling occurs not only at the MERC, but also at the sites of contact that the mitochondrion establishes with the plasma membrane or with other organelles. ${ }^{38-40}$ However, little is known on the length, thickness, dynamics and tethering of these subcellular structures. Nonetheless, it is tempting to speculate that $\mathrm{Ca}^{2+}$ regulation at these sites could occur through a change in the distance that separates the mitochondrion from its partnering membrane.

The diffusion laws and the principles discussed above are poised to guide the movement of any type of ion at the MERCs; for example, $\mathrm{Zn}^{2+}, 41,42$ which is uptaken by mitochondria to modulate ATP production. ${ }^{43,44}$ Another ion that accumulates in the mitochondrial matrix is copper. ${ }^{45}$ How this element is delivered to the organelle remains unclear, but evidence suggest that $\mathrm{Cu}^{+}$transport mechanisms exists in the Golgi and the ER. ${ }^{46,47}$ Therefore, it is conceivable that $\mathrm{Cu}^{+}$could be transferred from the ER to the mitochondrion by a still uncharacterized type of ion-MERC. $\mathrm{Cu}^{+}$is an essential cofactor of mitochondrial respiratory complexes; its loading in the redox center of the cytochrome $c$ oxidase is mediated by a sophisticated molecular mechanisms that involves $\mathrm{Cu}^{+}$metallochaperones like SCO1 and SCO2 (synthesis of cytochrome $c$ oxidase, factors 1 and 2). ${ }^{48-50}$ In this context, a specialized type of ion-MERC that is capable of $\mathrm{Cu}^{+}$transfer would be an ideal platform for controlled mitochondrial uptake of this essential element; recently developed sensors that measure metal ions in living systems ${ }^{51}$ could be used to address this possibility.

\section{The Lipid-MERC: A Site of Phospholipid Biosynthesis and Trafficking}

Organelles exchange lipids and this process requires their membranes to be in close proximity. For instance, in yeast, contacts between the mitochondria and the vacuole deliver lipids to the former. ${ }^{52} \mathrm{~A}$ role of the contacts between the mitochondrion and the ER in yeast lipid homeostasis has also been proposed and linked to the ERMES and the EMC protein complex; this possibility is debated and remains to be clarified. $^{52}$ In mammals, lipid transfer occurs also between mitochondria and the ER, at the sites of contact between these organelles. ${ }^{15,53,54}$ Here the lipid-MERC serves as a platform for lipid biosynthesis, as demonstrated by Jane Vance. ${ }^{10,14}$ At the MAM, phosphatidylserine is first synthesized in the ER by PSS1 and PSS2; then transferred to the mitochondrion, where a decarboxylase converts it to phosphatidylethanolamine; the latter is transferred back to the ER, where a methyltransferase, phosphatidylethanolamine $\mathrm{N}$-methyltransferase-2, converts it into phosphatidylcholine, a major component of the cell membrane. Subsequently, studies revealed that MAMs are also the site of triacylglycerol synthesis and steroidogenesis. ${ }^{15}$

Assuming that in a lipid-MERC the density of lipid biosynthetic enzymes and transporters is homogeneous, its output should be proportional to the size of its area. If so, any increase or decrease in the area of the lipid-MERC should be accompanied by a similar change in the amount of lipids synthesized by the lipid-MERC. In contrast, changes in the thickness of the lipid-MERC might have a role as an ON/OFF switch of the lipid transfer process. Two models have been proposed to mediate the shuttling of lipids between two membranes. ${ }^{55}$ The first operates via the tunneling of a lipid through hydrophobic channels formed by protein complexes, which would be disrupted upon the widening of the lipid-MERC cleft. The second requires the coating of the lipid by shuttling proteins that then would diffuse from one membrane to the other; in the latter case, the widening of the lipid-MERC cleft would subject the lipid transfer to Fick's and Einstein's laws that, as explained above, control their time and rate of delivery. Either model supports a paradigm where the width of the lipidMERC is a regulated parameter that serves to control lipid metabolism and homeostasis.

A potential cross-relationship between lipid and mitochondria metabolism has been proposed by Tasseva et al.:; ${ }^{.56}$ the authors showed that partial depletion of phosphatidylethanolamine causes extensive mitochondrial defects both in terms of morphology, and of respiratory capacity. Thus, impairment of lipid-MERC activity could impact on the activity of other MERC types and/or have a role in the maintenance of mitochondrial function and cell bioenergetics; a major implication of this concept is that dysfunctions in lipid-MERCs could be linked to the etiology of human disease. As mentioned above, MERCs and MAMs are two sides of the same coin; therefore, evidence on the role of lipid-MERCs in human diseases can be inferred by studies conducted on MAMs. Recent studies from Area-Gomez et al. ${ }^{30,57}$ have shown that the lipid-related function of the MAMs is increased in cells expressing mutated forms of familial AD proteins Presenilin-1 and Presenilin-2; also, that the presenilins and their gammasecretase activity are enriched at the MAM, where the 
A $\beta$ peptide is indeed also generated. ${ }^{58}$ Fibroblasts from $A D$ patients, whose symptoms include aberrant lipid metabolism, ${ }^{59}$ have more 'long' (50-200 nm) and 'very long' (>200 nm) MERCs, and increased lipid biosynthesis/transfer. These observations led to the formulation of the 'MAM hypothesis', which states that AD is essentially a disorder of ER-mitochondrial communication. ${ }^{60}$ These studies linked for the first time defective MAMs structure and function to a major neurodegenerative disease, ${ }^{30,57,60}$ validating previous evidence of a role of the MAMs in AD pathogenesis. ${ }^{61-63}$ and paving the way to studies showing upregulated expression of MAM-associated proteins in human and mouse AD brains prior to the appearance of amyloid plaques. ${ }^{64}$ Thus, altered lipid-MERC function might trigger amyloid plaques formation, which is at the core of the 'amyloid hypothesis'; in this scenario, the MAM and the amyloid hypothesis are not mutually exclusive, but place the loss of lipid homeostasis upstream of amyloid plaques deposition. Given the compelling evidence supporting the MAM hypothesis and the lack of therapies for AD patients, studies addressing this pathology as a brain metabolic disorder in lipid homeostasis are warranted.

\section{The Phago-MERC: The Autophagosome Point of Origin}

A recent study revealed that, in mammals, autophagosomes can form also at MERCs. ${ }^{65}$ After starvation, syntaxin- 17 binds and recruits at MERCs the preautophagosome/autophagosome markers ATG14-ATG5; indeed, ATG14 co-fractionates in the MAMs fraction upon starvation. ${ }^{65}$ Interestingly, the EM images published in this study localize ATG14 at MERCs in which the distance separating the two organelles is $\sim 50 \mathrm{~nm},{ }^{65}$ suggesting that the type of MERC that serves as the platform for autophagosome formation, the phago-MERC, cannot support ion or lipid exchanges.

The wider cleft at the phago-MERC might make sense in light of the fact that the initiation of the autophagic process requires sufficient space for the formation of the omegasome and of the isolation membrane. The initiation of autophagy requires indeed the presence of the class III PI3K complex and of the UNC51-like kinase (ULK) complex; ${ }^{66}$ the latter contains a large number of proteins, including the Ser/Thr kinases ULK1 and/or ULK2, ATG13, FAK family kinase-interacting protein of $200 \mathrm{kDa}$ and ATG101. Although the crystal structures of these complexes are not yet solved, the sterical constraints that they impose on the phago-MERC should be considerable, likely requiring the two organelles to be considerably spaced apart.

The existence of phago-MERCs raises the question of whether these structures are formed de novo upon autophagy initiation or, alternatively, whether dormant units exist under steady-state condition. Future studies on the plasticity of the phago-MERC number, length and thickness, as well as on the type of tether that keeps mitochondria and ER juxtaposed at the considerable distance of $50 \mathrm{~nm}$ will be key to the understanding of a process that is tightly interconnected with metabolic networks and redox homeostasis, and that is central to malignant transformation and cancer progression. ${ }^{67,68}$

\section{The Ribo-MERC: The Link between Mitochondria and The Ribosome-Containing Rough ER}

In the 1980s, EM studies showed that $80 \%$ or mitochondria have zones of close proximity with the ribosome-containing rough $E R(R E R){ }^{2,3}$ Since then, several groups reported the existence of RER-mitochondria contact sites, ${ }^{4,6,69}$ which we propose to call ribo-MERCs to harmonize and simplify the nomenclature. Here the width of the cleft separating the OMM from the RER varies between $\sim 50$ and $-80 \mathrm{~nm}$. Recent studies suggest that mitochondria are tethered to the smooth and rough ER through distinct mechanisms, with the Glycoprotein 78 E3 ubiquitin ligase protein, an ER membrane-anchored ubiquitin ligase (E3), being implicated in the formation of the ribo-MERCs. ${ }^{69}$ However, much remains unknown about these structure, which are often found to be in continuity with the 'normal', ribosome-free MERCs (Figure 1 and Figure 3). ${ }^{4}$ Future studies will need to focus on the function of these structures and on whether or not they remodel their length and thickness during ER stress or metabolic transitions as it is the case for other types of MERCs. ${ }^{4-6}$

\section{Conclusion and Perspectives}

In light of the data and of the laws of physics discussed here, MERCs appear to constitute a group of functionally specialized compartments whose activity and regulation is directed by the width of the cleft that separates the cytosolic face of the OMM and of the ER the MERC thickness. This parameter participates in specifying the function of the MERC and is, to date, the only available mean to speculate on the function(s) of a MERC or to distinguish among the various types of MERCs; indeed, any prediction on these matters remains heavily influenced by a considerable amount of guess work; furthermore, direct comparison of the MERC thickness measured in different studies should be done cautiously whenever the sample prepared for electron microscopy has been fixed by chemical cross-linking. However, our cryo-EM images clearly show that, within the same liver cell section, MERCs of different average thickness exist (Figure 4 and Figure 2).

Whereas the lipid-MERC is expected to be the narrowest type of MERC (possibly due to the molecular mechanism implicated in the transfer of largely hydrophobic molecules between the organelles), the phago-MERC is probably the widest type (due to the need to accommodate the large protein complexes that are required for omegasome biogenesis). Thus, EM images showing MERCs with a $10 \mathrm{~nm}$ gap might be predicted to be lipid-MERCs, but not phago-MERCs. A width of $\approx 20 \mathrm{~nm}$ can be ascribed to a $\mathrm{Ca}^{2+}-\mathrm{MERC}$. However, things could be complicated by the existence of 'dormant' lipidMERCs; that is, lipid-MERCs in stand-by, ready to start working as soon as the two membranes halve their distance (Figure 3). Likewise, a MERC with a cleft of $30 \mathrm{~nm}$ could be either a $\mathrm{Ca}^{2+}-\mathrm{MERC}$ or a dormant phago-MERC. Therefore, despite the complex and uncertain assignment of the various MERC types, MERCs dynamics are poised to act as key regulators of MERCs activities.

The existence of MERC's clefts whose width ranges from $\cong 10$ to $\cong 80 \mathrm{~nm}$ suggests that different types of mitochondriaER tethers exist, not least because the opposite scenario, One 
a

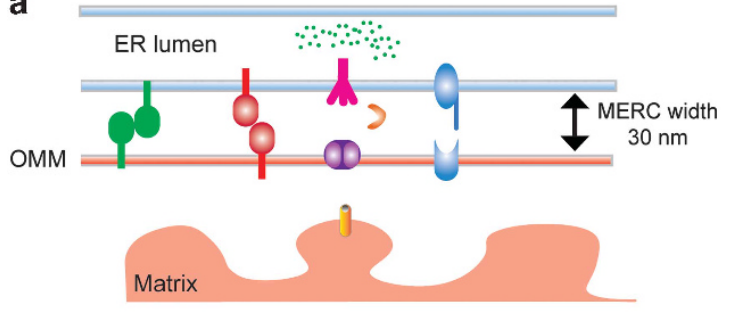

b

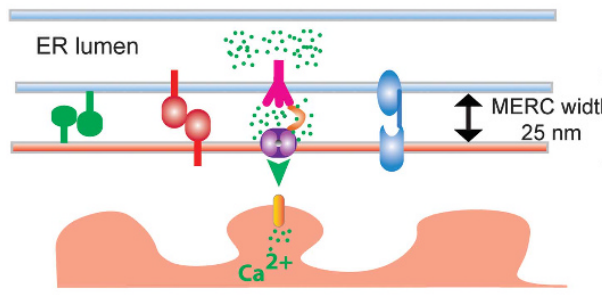

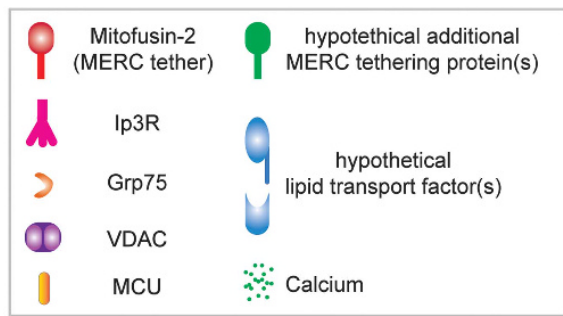

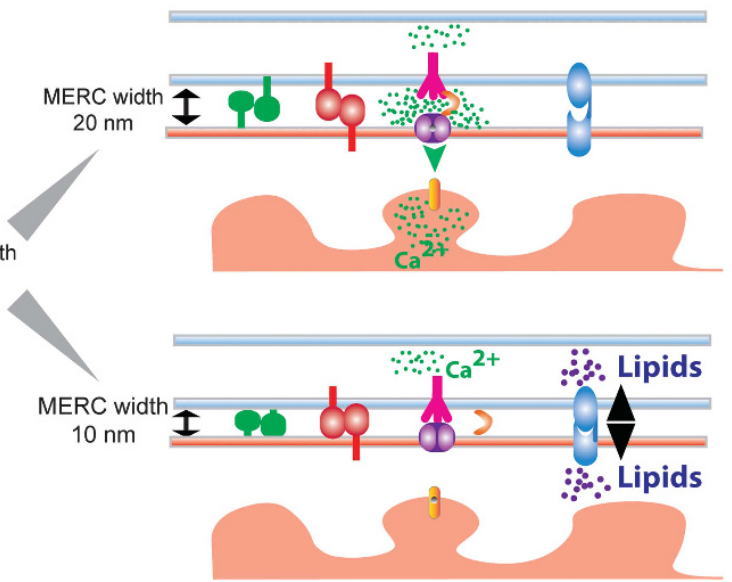

Figure 3 Model depicting how changes in the distance that separates the mitochondria from the ER could regulate MERCs function and/or level of activity. MERCs are dynamic structures; the width of the cleft changes depending on the metabolic state of the cell. This model shows how a too wide or too narrow distance between the organelles could affect the assembly of the complexes that drive calcium and lipid fluxes. A width of $30 \mathrm{~nm}$ is likely to result in a functionally dormant MERC (a); based on Fick and Einstein's diffusion laws, a cleft $20 \mathrm{~nm}$ wide would support higher rates and volumes of calcium uptake than one that is $25-\mathrm{nm}$ wide (b); however, a cleft of $10 \mathrm{~nm}$ would impair this process, due to steric hindrance of the proteins that form the complex that regulates its flux from the ER to the mitochondrion. Instead, a 10-nm wide MERC cleft could allow the formation of the proteins that mediate lipid transfer (c), which likely requires the tunneling of a lipid through hydrophobic channels formed by protein complexes anchored to the two juxtaposed membranes ${ }^{55}$

ring (tether) to rule them all (MERCs), ${ }^{70}$ would be untenable. First, because even if the width of the MERC's cleft is dynamic, ${ }^{6}$ a fivefold change in the distance that separates two organelles that are juxtaposed over an extended area of their surface $\left(4-11 \%^{4}\right)$ would be an energy-expensive cellular process (if not thermodynamically unattainable); second, because it would imply the existence of a universal molecular tether that, to date, does not seem to exist.

EM studies showed that the cleft of a MERC is typically dotted by electron-dense areas that are widely accepted to be formed by protein complexes (Figure 2). On this subject, it is important to stress the difference existing between a MERC tethering and a MERC resident protein. The first is required for MERC formation and to physically hold together the organelles (and, possibly, to dynamically regulate the MERC thickness - Figure 3); the latter is a protein that localizes in the cleft of the MERC and participates in its biochemical activity or functional regulation. A MERC resident protein might, directly or indirectly, participate in MERCs formation: for instance, by spacing apart the opposing membranes of the ER and the mitochondrion at a distance that allows the formation of MERC tethers; however, the structural composition of its domains does not warrant to consider it a bona fide MERC tether. In this respect, the IP3R-grp75-VDAC complex does not have a tethering role ${ }^{24,71}$ but, rather, a MERC spacing/filling function that derives from functionally coupling ER and mitochondria in $\mathrm{Ca}^{2+}$ exchanges. Whether MERC resident proteins are required for the assembly of $\mathrm{MERC}$ tethering protein complexes remains to be elucidated. Studies from multiple laboratories have shown that Mitofusin-2 (Mfn2) is a tether, $8,17,72$ likely of the $\mathrm{Ca}^{2+}-\mathrm{MERC} ;{ }^{72,73}$ studies arguing the opposite have recently emerged, ${ }^{74,75}$ but they could be reconciled by hypothesizing that the loss of the $\mathrm{Ca}^{2+}-\mathrm{MERC}$ tether triggers compensatory responses during which another MERC tether rescues the phenotype associated to the loss of Mfn2. Accordingly, in cultured Mfn2-/- MEFs (mouse embryonic fibroblasts), lipid-MERCs in a 'resting state' (say, with a cleft of 17-20 nm-see Figure $1 \mathrm{~b}$ of ref. 75 ), could somewhat complement the loss of Mfn2-mediated tethering. In mouse hepatocytes, $\approx 10-$ nm-thick MERCs are frequently observed (our unpublished data; Figure 4); immortalized Mfn2-/- cells could have more of them, some of which might mediate $\mathrm{Ca}^{2+}$-transfer by widening 1.5-2-folds into a 'relaxed' state. In such a MERCs 'multi-tether' model, MERC thickness can change up to twofold, ${ }^{6}$ a possibility that is plausible under a protein-complex structural point of view. Future studies investigating the impact of cell confluence and metabolism on the width of the MERCs of Mfn2-/- MEFs will provide information on the role of MERCs plasticity in cell physiology.

Interestingly, Mfn2 knockout leads to permanent ER stress; ${ }^{76,77}$ this is manifested with an increase in the amount of releasable $\mathrm{Ca}^{2+}$ from the ER lumen and with a $30 \%$ increase in the volume of ER membranes. ${ }^{74}$ ER stress is well known to 

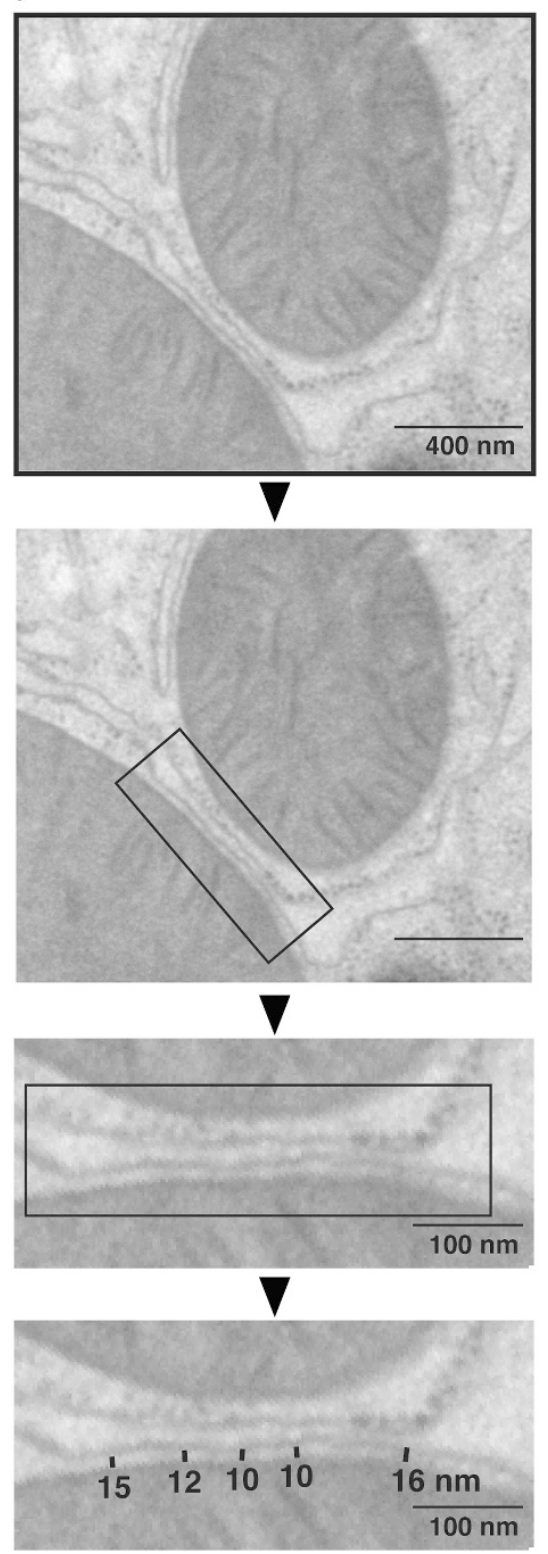

b
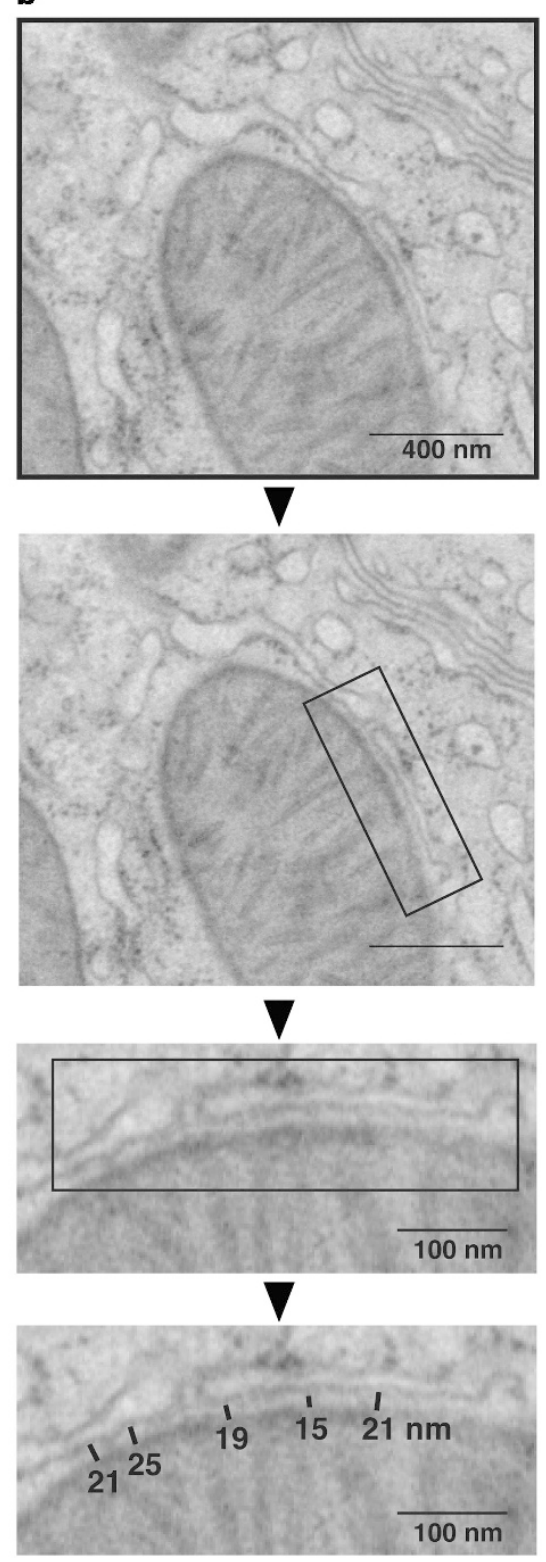

Figure 4 The width of the MERC cleft is rather uniform, but varies from MERC to MERC. Representative cryo-EM images of mouse hepatocytes ${ }^{4}$ showing a MERC with an average constant width of $\approx 12 \mathrm{~nm}(\mathbf{a})$ and $\approx 20 \mathrm{~nm}(\mathbf{b})$. As the distance between the organelles is a regulated structural parameter of the cell and is subjected to Fick and Einstein's diffusion laws, it is conceivable that the two MERCs shown here could have different function and/or level of activity

increase the length and reduce the thickness of the MERCs, ${ }^{6}$ a spatial reorganization that correlates with increased ATP levels, oxygen consumption, reductive power and mitochondrial $\mathrm{Ca}^{2+}$ uptake. ${ }^{5,8}$ Strikingly, however, Mfn2-/- MEFs consume less oxygen than controls, ${ }^{78}$ unlike what is observed upon ER stress. ${ }^{5}$ The administration of chemical chaperones known to alleviate ER stress and the knockdown of the ER stress kinase PERK can partially rescue components of the Mfn2-/- phenotype, including the reduced oxygen consumption rates; ${ }^{77,78}$ taken together these findings suggest that although ablation of Mfn2 causes ER stress, its effect is somewhat different from what happens during 'normal' ER stress, a possibility consistent with an altered quality/type of tethering. ${ }^{8}$ Evidence that during ER stress and metabolic transitions MERCs can change length ${ }^{4}$ and thickness (see above) support the concept that MERCs dynamics must have a critical role in the Mfn2 knockout phenotype.

The ER is an assembly of distinct membrane domains that execute diverse functions: the ER quality control compartment (ERQC), where ER-associated degradation (ERAD) occurs, the plasma membrane-associated membrane (PAM), and the MERCs. These domains are characterized by unique proteomes, indicating that their composition is the result of a regulated process that involves specific sorting and assembly mechanisms. How proteins are targeted at the MERCs has remained elusive till recently, when Lynes et al. ${ }^{79,80}$ 
demonstrated that palmitoylation of key cysteine residues located near the membrane-spanning domain of ER-localized proteins is a key process to enrich them on the MAM. Whether and how protein palmitoylation is integrated into the mechanisms that regulate changes in MERCs length and thickness during metabolic transitions ${ }^{4}$ remains to be established.

The fact that mitochondria and the ER are tethered together allows the biochemical purification of the MERCs as MAMs. MAMs purification yields the ensemble of membranes that are bound to the $E R$, including the lipid-MERCs, the ion-MERCs, the phago-MERCs, the ribo-MERCs and the sites where ER tubules contact mitochondria to mediate the Drp-1-dependent constriction that guides mitochondria division, ${ }^{81,82}$ the fissionMERC. As such, the current MAM proteomes, ${ }^{83,84}$ are representative of the protein collections of all types of MERCs in the tissue and cell type from which the MAMs were isolated. Similarly, localization of major protein complexes like the $\gamma$-secretase ${ }^{30,57}$ and mTORC2 $^{85}$ at the MAMs will need to be investigated by immunogold analysis, to associate their localization to a specific MERC thickness and, therefore, function.

In yeast, 3D reconstruction of the fission-MERC define this subcellular compartment as the site where the ER membrane comes within $30 \mathrm{~nm}$ of the OMM and ribosomes are excluded. Here the ER appears to wrap around mitochondria to varying degrees, in some cases nearly circumscribing completely the organelle and constricting it to a diameter of $138-146 \mathrm{~nm}$ (versus 193-215 nm in the absence of a fission-MERC). ${ }^{81}$ In mammals, correlative cryogenic fluorescence microscopy and soft X-ray tomography (CFM-SXT) revealed the presence of ER extensions $168 \mathrm{~nm}$ long and $80 \mathrm{~nm}$ in diameter that contact mitochondria at vision sites enriched in the mitochondrial dynamics proteins Mid49 and Mid51 (mitochondrial dynamics proteins of 49 and $51 \mathrm{kDa}) .^{82}$ By implication, a MERC with a length longer than $100 \mathrm{~nm}$ should not be a fission-MERC.

The possibility that MERCs have specialized functions does not exclude that a MERC could be preprogrammed (and reprogrammed) to execute multiple tasks. A MERC with a cleft of $20 \mathrm{~nm}$ could be a working $\mathrm{Ca}^{2+}-\mathrm{MERC}$. Such a MERC, in principle, could also host the protein complexes required for lipid synthesis/transfer. Upon halving the MERC width to $10 \mathrm{~nm}$, these complexes would then be primed to start their functions while $\mathrm{Ca}^{2+}$ transfer, instead, would stop. Under such scenario, therefore, the plasticity of the MERC thickness could serve to switch MERC function (Figure 3).

Recent studies have suggested that effective $\mathrm{Ca}^{2+}$ transfer and generation of $\mathrm{Ca}^{2+}$ signals depends on an optimal theoretical distance of $30-85 \mathrm{~nm}$ between IP3R and MCU. ${ }^{86}$ Therefore, when studying the $\mathrm{Ca}^{2+}-\mathrm{MERC}$, the spatial relationship between the OMM and the highly impermeable inner mitochondrial membrane (IMM) must also be taken into account because MCU localizes there. ${ }^{19,20,87}$ Electron tomography studies of mitochondria from various species and tissues showed that sites of close proximity ('contacts') between the OMM and the IMM exist; here, the two membranes are separated by a gap of $10-14 \mathrm{~nm},{ }^{88,89}$ a distance that supports the efficient flux of $\mathrm{Ca}^{2+}$ from the ER lumen to the mitochondrial matrix at the $\mathrm{Ca}^{2+}-\mathrm{MERC}$. An even narrower distance between the IMM and the OMM might explain why in certain tissues $\mathrm{Ca}^{2+}$ uptake occurs even if the distance between the organelles is wide, as in the skeletal muscle, where the cleft separating the mitochondrial surface from the Ryanodine Receptor on the junctional sarcoplasmic reticulum (jSR) is $130 \mathrm{~nm}$ ( $37 \mathrm{~nm}$ in the cardiac muscle). In these cells, Eisner et al. proposed that the two mitochondrial membranes are in real contact, forming an arrangement of the jSR-OMM-IMM that, ultimately, provide a 'highway' for $\mathrm{Ca}^{2+}$ delivery from the SR to the mitochondrial matrix. ${ }^{90}$ Hence, similar to the distance between the ER and the OMM, the distance between the OMM and the IMM might also be a regulated structural parameter, a possibility that, in turn, would support the existence of a molecular mechanism that organizes the spatial 'sandwich-like' arrangement and, perhaps, the joint tethering, of the ER, OMM and IMM at the sites of $\mathrm{Ca}^{2+}$ transfer. Such three-membrane structure could regulate the activity of lipid-MERCs because, like MCU, enzymes involved in MERC-mediated lipid biosynthesis are in the IMM. ${ }^{15}$

Recent studies have shown that the lipid composition of the MAMs is unique, resembling that of intracellular detergentresistant lipid raft (LR)-like domain. ${ }^{30}$ Extending these findings to the MERCs should be done keeping in mind that although lipid-MERCs might have a LR-like composition, the same might not be the case for other types of MERCs. LRs are enriched of cholesterol and sphingolipids: their unique composition confers them a ordered structure that, ultimately, compartmentalize and stabilize the molecular machinery that they contain. Structural insights on the protein complexes harbored within the MERCs will also provide insights on whether and how the lipid composition of a MERC participates in defining its function. Our study has shown that loss of mammalian target of rapamycin complex (mTORC) signaling activates a program that doubles the length of the MERCs in $<1 \mathrm{~h} .{ }^{4}$ We currently do not know in how much time LR-like domain can be formed; so, it is impossible to speculate whether the longer MERCs that are formed upon loss of mTORC1 signaling have the same lipid composition of the shorter MERCs that serve the cell in the opposite metabolic state. Nonetheless, lipidomics and proteomics analysis from mouse liver MAMs isolated at different postprandial times is possible: ${ }^{4}$ such studies will provide new insights on MERCs lipid and proteomic composition as well as on LR biogenesis.

\section{Conflict of Interest}

The authors declare no conflict of interest.

Acknowledgements. Work in the Pellegrini lab is supported by a grant from the Canadian Institutes of Health Research (MOP-82718). L.P is indebted to S.R. for research support, to Dr. Katalin Toth and Philippe Lemieux for assistance with EM analysis, and to the scientific direction of the CRIUSMQ for paying the publication fees of this article.

1. Copeland DE, Dalton AJ. An association between mitochondria and the endoplasmic reticulum in cells of the pseudobranch gland of a teleost. J Biophys Biochem Cytol 1959; 5 : 393-396.

2. Montisano DF, Cascarano J, Pickett CB, James TW. Association between mitochondria and rough endoplasmic reticulum in rat liver. Anat Rec 1982; 203: 441-450.

3. Pickett CB, Montisano D, Eisner D, Cascarano J. The physical association between rat liver mitochondria and rough endoplasmic reticulum. I. Isolation, electron microscopic 
examination and sedimentation equilibrium centrifugation analyses of rough endoplasmic reticulum-mitochondrial complexes. Exp Cell Res 1980; 128: 343-352.

4. Sood A, Jeyaraju VD, Prudent J, Caron A, Lemieux P, McBride HM et al.. A Mitofusin-2dependent inactivating cleavage of Opa1 links changes in mitochondria cristae and ER contacts in the postprandial liver. Proc Natl Acad Sci USA 2014; 111: 16017-16022.

5. Bravo R, Vicencio JM, Parra V, Troncoso R, Munoz JP, Bui M et al. Increased ERmitochondrial coupling promotes mitochondrial respiration and bioenergetics during early phases of ER stress. J Cell Sci 2011; 124: 2143-2152.

6. Csordas G, Renken C, Varnai P, Walter L, Weaver D, Buttle KF et al. Structural and functional features and significance of the physical linkage between $E R$ and mitochondria. J Cell Biol 2006; 174: 915-921.

7. Rizzuto R, Pinton P, Carrington W, Fay FS, Fogarty KE, Lifshitz LM et al. Close contacts with the endoplasmic reticulum as determinants of mitochondrial Ca2+ responses. Science 1998 280: 1763-1766.

8. de Brito OM, Scorrano L. Mitofusin 2 tethers endoplasmic reticulum to mitochondria. Nature 2008; 456: 605-610.

9. Gilady SY, Bui M, Lynes EM, Benson MD, Watts R, Vance JE et al. Ero1alpha requires oxidizing and normoxic conditions to localize to the mitochondria-associated membrane (MAM). Cell Stress Chaperone 2010; 15: 619-629.

10. Vance JE. Phospholipid synthesis in a membrane fraction associated with mitochondria. J Biol Chem 1990; 265: 7248-7256.

11. Cui Z, Vance JE, Chen MH, Voelker DR, Vance DE. Cloning and expression of a novel phosphatidylethanolamine $\mathrm{N}$-methyltransferase. A specific biochemical and cytological marker for a unique membrane fraction in rat liver. J Biol Chem 1993; 268 : 16655-16663.

12. Rusinol $A E$, Cui $Z$, Chen $M H$, Vance JE. A unique mitochondria-associated membrane fraction from rat liver has a high capacity for lipid synthesis and contains pre-Golgi secretory proteins including nascent lipoproteins. J Biol Chem 1994; 269: 27494-27502.

13. Shiao YJ, Lupo G, Vance JE. Evidence that phosphatidylserine is imported into mitochondria via a mitochondria-associated membrane and that the majority of mitochondria phosphatidylethanolamine is derived from decarboxylation of phosphatidylserine. $J$ Biol Chem 1995; 270: 11190-11198.

14. Vance JE. Newly made phosphatidylserine and phosphatidylethanolamine are preferentially translocated between rat liver mitochondria and endoplasmic reticulum. J Biol Chem 1991; 266: 89-97.

15. Vance JE. MAM (mitochondria-associated membranes) in mammalian cells: lipids and beyond2014 Biochim Biophys Acta 2014 ;1841: 595-609.

16. Giorgi C, Missiroli S, Patergnani S, Duszynski J, Wieckowski MR, Pinton P. Mitochondriaassociated membranes: composition, molecular mechanisms, and physiopathologica implications. Antioxid Redox Signal 2015; 22: 995-1019.

17. Naon D, Scorrano L. At the right distance: ER-mitochondria juxtaposition in cell life and death. Biochim Biophys Acta 2014; 1843: 2184-2194.

18. Raturi $A$, Simmen $T$. Where the endoplasmic reticulum and the mitochondrion tie the knot: the mitochondria-associated membrane (MAM). Biochim Biophys Acta 2013; 1833 213-224.

19. Baughman JM, Perocchi F, Girgis HS, Plovanich M, Belcher-Timme CA, Sancak Y et al. Integrative genomics identifies MCU as an essential component of the mitochondrial calcium uniporter. Nature 2011; 476: 341-345.

20. De Stefani D, Raffaello A, Teardo E, Szabo I, Rizzuto R. A forty-kilodalton protein of the inner membrane is the mitochondrial calcium uniporter. Nature 2011; 476: 336-340.

21. Filadi R, Pozzan T. Generation and functions of second messengers microdomains. Cell Calcium 2015; 58: 405-414.

22. Einstein A, Fürth R, Cowper AD. Investigations on the Theory of the Brownian Movement Methuen \& Co. Ltd: London, UK, 1926.

23. Csordas G, Varnai P, Golenar T, Roy S, Purkins G, Schneider TG et al. Imaging interorganelle contacts and local calcium dynamics at the ER-mitochondrial interface. Mo Cell 2010; 39: 121-132.

24. Szabadkai G, Bianchi K, Varnai P, De Stefani D, Wieckowski MR, Cavagna D et al. Chaperone-mediated coupling of endoplasmic reticulum and mitochondrial $\mathrm{Ca} 2+$ channels. J Cell Biol 2006; 175: 901-911.

25. Giacomello M, Drago I, Bortolozzi M, Scorzeto M, Gianelle A, Pizzo P et al. Ca2+ hot spots on the mitochondrial surface are generated by $\mathrm{Ca} 2+$ mobilization from stores, but not by activation of store-operated Ca2+ channels. Mol Cell 2010; 38: 280-290.

26. Naraghi M, Neher E. Linearized buffered $\mathrm{Ca} 2+$ diffusion in microdomains and its implications for calculation of [Ca2+] at the mouth of a calcium channel. J Neurosci 1997; 17: 6961-6973.

27. Cali T, Ottolini D, Negro A, Brini M. Enhanced parkin levels favor ER-mitochondria crosstalk and guarantee $\mathrm{Ca}(2+)$ transfer to sustain cell bioenergetics. Biochim Biophys Acta 2013 1832: 495-508.

28. Cardenas C, Miller RA, Smith I, Bui T, Molgo J, Muller M et al. Essential regulation of cell bioenergetics by constitutive InsP3 receptor Ca2+ transfer to mitochondria. Cell 2010; 142 270-283.

29. Cogliati S, Frezza C, Soriano ME, Varanita T, Quintana-Cabrera R, Corrado M et al. Mitochondrial cristae shape determines respiratory chain supercomplexes assembly and respiratory efficiency. Cell 2013; 155: 160-171.

30. Area-Gomez E, Del Carmen Lara Castillo M, Tambini MD, Guardia-Laguarta C, de Groof AJ, Madra $\mathrm{M}$ et al. Upregulated function of mitochondria-associated ER membranes in Alzheimer disease. EMBO J 2012; 31: 4106-4123.
31. Ottolini D, Cali T, Negro A, Brini M. The Parkinson disease-related protein DJ-1 counteracts mitochondrial impairment induced by the tumour suppressor protein $\mathrm{p} 53$ by enhancing endoplasmic reticulum-mitochondria tethering. Hum Mol Genet 2013; 22 : 2152-2168.

32. Giorgi C, Bonora M, Sorrentino G, Missiroli S, Poletti F, Suski JM et al. p53 at the endoplasmic reticulum regulates apoptosis in a $\mathrm{Ca} 2+-d e p e n d e n t$ manner. Proc Natl Acad Sci USA 2015; 112: 1779-1784

33. Di Benedetto G, Pendin D, Greotti E, Pizzo P, Pozzan T. Ca2+ and cAMP cross-talk in mitochondria. J Physiol 2014; 592: 305-312.

34. Jeyaraju DV, Cisbani G, Pellegrini L. Calcium regulation of mitochondria motility and morphology. Biochim Biophys Acta 2009; 1787: 1363-1373.

35. Rizzuto R, De Stefani D, Raffaello A, Mammucari C. Mitochondria as sensors and regulators of calcium signalling. Nat Rev Mol Cell Biol 2012; 13: 566-578.

36. Filippin L, Magalhaes PJ, Di Benedetto G, Colella M, Pozzan T. Stable interactions between mitochondria and endoplasmic reticulum allow rapid accumulation of calcium in a subpopulation of mitochondria. J Biol Chem 2003; 278: 39224-39234.

37. Jiang QX, Thrower EC, Chester DW, Ehrlich BE, Sigworth FJ. Three-dimensional structure of the type 1 inositol 1,4,5-trisphosphate receptor at $24 \mathrm{~A}$ resolution. EMBO J 2002; 21: 3575-3581.

38. Kar $\mathrm{P}$, Parekh $\mathrm{AB}$. Distinct spatial $\mathrm{Ca} 2+$ signatures selectively activate different NFAT transcription factor isoforms. Mol Cell 2015; 58: 232-243.

39. Nunes P, Cornut D, Bochet V, Hasler U, Oh-Hora M, Waldburger JM et al. STIM1 juxtaposes ER to phagosomes, generating $\mathrm{Ca}(2)(+)$ hotspots that boost phagocytosis. Curr Biol 2012; 22: 1990-1997.

40. Park CY, Hoover PJ, Mullins FM, Bachhawat P, Covington ED, Raunser S et al. STIM1 clusters and activates CRAC channels via direct binding of a cytosolic domain to Orai1. Cell 2009; 136: 876-890.

41. Chabosseau P, Tuncay E, Meur G, Bellomo EA, Hessels A, Hughes S et al. Mitochondrial and ER-targeted eCALWY probes reveal high levels of free Zn2+. ACS Chem Biol 2014; 9: 2111-2120.

42. McCranor BJ, Bozym RA, Vitolo MI, Fierke CA, Bambrick L, Polster BM et al. Quantitative imaging of mitochondrial and cytosolic free zinc levels in an in vitro model of ischemia/ reperfusion. J Bioenerg Biomembr 2012; 44: 253-263.

43. Costello LC, Liu Y, Franklin RB, Kennedy MC. Zinc inhibition of mitochondrial aconitase and its importance in citrate metabolism of prostate epithelial cells. J Biol Chem 1997; 272 : 28875-28881.

44. Kelleher SL, McCormick NH, Velasquez V, Lopez V. Zinc in specialized secretory tissues: roles in the pancreas, prostate, and mammary gland. Adv Nutr 2011; 2: 101-111.

45. Cobine PA, Ojeda LD, Rigby KM, Winge DR. Yeast contain a non-proteinaceous pool of copper in the mitochondrial matrix. J Biol Chem 2004; 279: 14447-14455.

46. Bingham MJ, Burchell A, McArdle HJ. Identification of an ATP-dependent copper transport system in endoplasmic reticulum vesicles isolated from rat liver. J Physiol 1995; 482(Pt 3): 583-587.

47. Bull PC, Thomas GR, Rommens JM, Forbes JR, Cox DW. The Wilson disease gene is a putative copper transporting P-type ATPase similar to the Menkes gene. Nat Genet 1993; 5: 327-337.

48. Hlynialuk CJ, Ling B, Baker ZN, Cobine PA, Yu LD, Boulet A. The mitochondrial metallochaperone SCO1 is required to sustain expression of the high-affinity copper transporter CTR1 and preserve copper homeostasis. Cell Rep 2015; 10: 933-943.

49. Horng YC, Leary SC, Cobine PA, Young FB, George GN, Shoubridge EA et al. Human Sco1 and Sco2 function as copper-binding proteins. J Biol Chem 2005; 280: 34113-34122.

50. Leary SC, Kaufman BA, Pellecchia G, Guercin GH, Mattman A, Jaksch M et al. Human SCO1 and SCO2 have independent, cooperative functions in copper delivery to cytochrome c oxidase. Hum Mol Genet 2004; 13: 1839-1848.

51. Carter KP, Young AM, Palmer AE. Fluorescent sensors for measuring metal ions in living systems. Chem Rev 2014; 114: 4564-4601.

52. Lang A, John Peter AT, Kornmann B. ER-mitochondria contact sites in yeast: beyond the myths of ERMES. Curr Opin Cell Biol 2015; 35: 7-12.

53. Flis VV, Daum G. Lipid transport between the endoplasmic reticulum and mitochondria. Cold Spring Harb Perspect Biol 2013; 5: a013235

54. Scharwey M, Tatsuta T, Langer T. Mitochondrial lipid transport at a glance. J Cell Sci 2013; 126: $5317-5323$.

55. Schauder CM, Wu X, Saheki Y, Narayanaswamy P, Torta F, Wenk MR et al. Structure of a lipid-bound extended synaptotagmin indicates a role in lipid transfer. Nature 2014; 510: 552-555.

56. Tasseva G, Bai HD, Davidescu M, Haromy A, Michelakis E, Vance JE. Phosphatidylethanolamine deficiency in Mammalian mitochondria impairs oxidative phosphorylation and alters mitochondrial morphology. J Biol Chem 2013; 288: 4158-4173.

57. Area-Gomez E, de Groof AJ, Boldogh I, Bird TD, Gibson GE, Koehler CM et al. Presenilins are enriched in endoplasmic reticulum membranes associated with mitochondria. $A m \mathrm{~J}$ Pathol 2009; 175: 1810-1816.

58. Schreiner B, Hedskog L, Wiehager B, Ankarcrona M. Amyloid-beta peptides are generated in mitochondria-associated endoplasmic reticulum membranes. J Alzheimers Dis 2015; 43: 369-374.

59. Mapstone M, Cheema AK, Fiandaca MS, Zhong X, Mhyre TR, MacArthur LH et al. Plasma phospholipids identify antecedent memory impairment in older adults. Nat Med 2014; 20: 415-418. 
60. Schon EA, Area-Gomez E. Mitochondria-associated ER membranes in Alzheimer disease. Mol Cell Neurosci 2013; 55: 26-36.

61. Zampese E, Fasolato C, Kipanyula MJ, Bortolozzi M, Pozzan T, Pizzo P. Presenilin 2 modulates endoplasmic reticulum (ER)-mitochondria interactions and $\mathrm{Ca} 2+$ cross-talk. Proc Natl Acad Sci USA 2011; 108: 2777-2782.

62. Zampese E, Fasolato C, Pozzan T, Pizzo P. Presenilin-2 modulation of ER-mitochondria interactions: FAD mutations, mechanisms and pathological consequences. Commun Integr Biol 2011; 4: 357-360.

63. Zampese E, Pizzo P. Intracellular organelles in the saga of Ca2+ homeostasis: different molecules for different purposes? Cell Mol Life Sci 2012; 69: 1077-1104.

64. Hedskog L, Pinho CM, Filadi R, Ronnback A, Hertwig L, Wiehager B et al. Modulation of the endoplasmic reticulum-mitochondria interface in Alzheimer's disease and related models. Proc Natl Acad Sci USA 2013; 110: 7916-7921.

65. Hamasaki M, Furuta N, Matsuda A, Nezu A, Yamamoto A, Fujita N et al. Autophagosomes form at ER-mitochondria contact sites. Nature 2013; 495: 389-393.

66. Lamb CA, Yoshimori T, Tooze SA. The autophagosome: origins unknown, biogenesis complex. Nat Rev Mol Cell Biol 2013; 14: 759-774.

67. Filomeni G, De Zio D, Cecconi F. Oxidative stress and autophagy: the clash between damage and metabolic needs. Cell Death Differ 2015; 22: 377-388.

68. Galluzzi L, Pietrocola F, Bravo-San Pedro JM, Amaravadi RK, Baehrecke EH, Cecconi F et al. Autophagy in malignant transformation and cancer progression. EMBO J 2015; 34: 856-880.

69. Wang PT, Garcin PO, Fu M, Masoudi M, St-Pierre P, Pante N et al. Distinct mechanisms controlling rough and smooth endoplasmic reticulum contacts with mitochondria. J Cell Sci 2015; 128: 2759-2765.

70. Tolkien JRR. The Lord of the Rings. Allen \& Unwin: London, UK, 1954.

71. Rapizzi E, Pinton P, Szabadkai G, Wieckowski MR, Vandecasteele G, Baird G et al. Recombinant expression of the voltage-dependent anion channel enhances the transfer of Ca2+ microdomains to mitochondria. J Cell Biol 2002; 159: 613-624.

72. Sugiura A, Nagashima S, Tokuyama T, Amo T, Matsuki Y, Ishido $S$ et al. MITOL; regulates endoplasmic reticulum-mitochondria contacts via Mitofusin2. Mol Cell 2013; 51 20-34.

73. Chen Y, Csordas G, Jowdy C, Schneider TG, Csordas N, Wang W et al. Mitofusin 2containing mitochondrial-reticular microdomains direct rapid cardiomyocyte bioenergetic responses via interorganelle $\mathrm{Ca}(2+)$ crosstalk. Circ Res 2012; 111: 863-875.

74. Cosson P, Marchetti A, Ravazzola M, Orci L. Mitofusin-2 independent juxtaposition of endoplasmic reticulum and mitochondria: an ultrastructural study. PLoS One 2012; 7: e46293.

75. Filadi R, Greotti E, Turacchio G, Luini A, Pozzan T, Pizzo P. Mitofusin 2 ablation increases endoplasmic reticulum-mitochondria coupling. Proc Natl Acad Sci USA 2015; 112 E2174-E2181.

76. Ngoh GA, Papanicolaou KN, Walsh K. Loss of mitofusin 2 promotes endoplasmic reticulum stress. J Biol Chem 2012; 287: 20321-20332.
77. Schneeberger M, Dietrich MO, Sebastian D, Imbernon M, Castano C, Garcia A et al. Mitofusin 2 in POMC neurons connects ER stress with leptin resistance and energy imbalance. Cell 2013; 155: 172-187.

78. Munoz JP, Ivanova S, Sanchez-Wandelmer J, Martinez-Cristobal P, Noguera E, Sancho A et al. Mfn2 modulates the UPR and mitochondrial function via repression of PERK. EMBO J 2013; 32: 2348-2361.

79. Lynes EM, Bui M, Yap MC, Benson MD, Schneider B, Ellgaard L et al. Palmitoylated TMX and calnexin target to the mitochondria-associated membrane. EMBO J 2012; 31 $457-470$.

80. Lynes EM, Raturi A, Shenkman M, Ortiz Sandoval C, Yap MC, Wu J et al. Palmitoylation is the switch that assigns calnexin to quality control or ER Ca2+ signaling. J Cell Sci2013; 126: 3893-3903.

81. Friedman JR, Lackner LL, West M, DiBenedetto JR, Nunnari J, Voeltz GK. ER tubules mark sites of mitochondrial division. Science 2011; 334: 358-362.

82. Elgass KD, Smith EA, LeGros MA, Larabell CA, Ryan MT. Analysis of ER-mitochondria contacts using correlative fluorescence microscopy and soft X-ray tomography of mammalian cells. J Cell Sci 2015; 128: 2795-2804.

83. Horner SM, Wilkins C, Badil S, Iskarpatyoti J, Gale M Jr. Proteomic analysis of mitochondrial-associated ER membranes (MAM) during RNA virus infection reveals dynamic changes in protein and organelle trafficking. PLoS One 2015; 10: e0117963.

84. Liu Z, Du X, Deng J, Gu M, Hu H, Gui M et al. The interactions between mitochondria and sarcoplasmic reticulum and the proteome characterization of mitochondrion-associated membrane from rabbit skeletal muscle. Proteomics 2015; 15: 2701-2704.

85. Betz C, Stracka D, Prescianotto-Baschong C, Frieden M, Demaurex N, Hall MN. Feature Article: mTOR complex 2-Akt signaling at mitochondria-associated endoplasmic reticulum membranes (MAM) regulates mitochondrial physiology. Proc Natl Acad Sci USA 2013; 110: 12526-12534.

86. Qi H, Li L, Shuai J. Optimal microdomain crosstalk between endoplasmic reticulum and mitochondria for $\mathrm{Ca}(2+)$ oscillations. Sci Rep 2015; 5: 7984.

87. De Stefani D, Patron M, Rizzuto R. Structure and function of the mitochondrial calcium uniporter complex. Biochim Biophys Acta 2015; 1853: 2006-2011.

88. Gold VA, leva R, Walter A, Pfanner N, van der Laan M, Kuhlbrandt W. Visualizing active membrane protein complexes by electron cryotomography. Nat Commun 2014; 5: 4129.

89. Reichert AS, Neupert W. Contact sites between the outer and inner membrane of mitochondria-role in protein transport. Biochim Biophys Acta 2002; 1592: 41-49.

90. Eisner V, Csordas G, Hajnoczky G. Interactions between sarco-endoplasmic reticulum and mitochondria in cardiac and skeletal muscle - pivotal roles in $\mathrm{Ca}(2)(+)$ and reactive oxygen species signaling. J Cell Sci 2013; 126: 2965-2978.

91. Muoio DM. Metabolic inflexibility: when mitochondrial indecision leads to metabolic gridlock Cell 2014; 159: 1253-1262. 